\title{
tPA Is a Potent Mitogen for Renal Interstitial Fibroblasts
}

\section{Role of $\beta 1$ Integrin/Focal Adhesion Kinase Signaling}

\author{
Sha Hao, ${ }^{* \dagger}$ Hongmei Shen, ${ }^{\ddagger}$ Yayi Hou, ${ }^{\dagger}$ \\ Wendy M. Mars, ${ }^{*}$ and Youhua Liu* \\ From the Departments of Pathology, ${ }^{*}$ and Surgery, ${ }^{\ddagger}$ University of \\ Pittsburgh School of Medicine, Pittsburgh, Pennsylvania; and the \\ Immunology and Reproductive Biology Laboratory, ${ }^{\dagger}$ Nanjing \\ University Medical School, Nanjing, China
}

Proliferation and expansion of interstitial fibroblasts are predominant features of progressive chronic kidney diseases. However, how interstitial fibroblast proliferation is controlled remains ambiguous. Here we show that tissue-type plasminogen activator (tPA) is a potent mitogen that promotes interstitial fibroblast proliferation through a cascade of signaling events. In vitro, tPA promoted cell proliferation of rat kidney fibroblasts (NRK-49F), as assessed by cell counting, cell proliferation assay, and bromodeoxyuridine labeling. tPA also accelerated NRK-49F cell cycle progression. Fibroblast proliferation induced by tPA was associated with an increased expression of numerous proliferation-related genes, including c-fos, c-myc, proliferating cell nuclear antigen, and cyclin D1. The mitogenic effect of tPA was independent of its protease activity, but required LDL receptor-related protein 1. Interestingly, inhibition of $\beta 1$ integrin signaling prevented tPA-mediated fibroblast proliferation. tPA rapidly induced tyrosine phosphorylation of focal adhesion kinase (FAK), which led to activation of its downstream mitogen-activated protein kinase signaling. Blockade of FAK, but not integrin-linked kinase, abolished the tPA-triggered extracellular signalregulated protein kinase $1 / 2$ activation, proliferationrelated gene induction, and fibroblast proliferation. In vivo, proliferation of interstitial myofibroblasts in tPA null mice was attenuated after obstructive injury, compared with the wild-type controls. These studies illustrate that tPA is a potent mitogen that promotes renal interstitial fibroblast proliferation through LDL receptor-related protein 1-mediated $\beta 1$ integrin and FAK signaling. (Am J Pathol 2010, 177:1164-1175; DOI: 10.2353/ajpath.2010.091269)

Interstitial fibrosis, characterized by an excessive production and deposition of extracellular matrix in renal tubulointerstitial compartment, is considered a common converging outcome of a wide variety of progressive chronic kidney diseases. ${ }^{1-3}$ As interstitial fibroblasts are the principal matrix-producing cells, the degree of fibroblast proliferation and expansion is likely a major determining factor controlling the progression of renal fibrosis and the decline of kidney function. ${ }^{4-8}$ Interstitial fibroblasts in normal kidney are scarce in numbers and quiescent in nature. However, they become activated and undergo cell proliferation after chronic renal injury, resulting in an expansion of this fibrogenic cell population. ${ }^{9-11}$ Although recent studies indicate that fibroblasts may come from different sources including tubular epithelium via epithelial to mesenchymal transition, ${ }^{12-14}$ it is highly likely that the replication of residential fibroblasts remains a major avenue leading to interstitial fibroblast expansion under pathological conditions. In this context, identification of key mediators that control renal fibroblast proliferation and delineation of the underlying mechanism would be essential in unraveling the pathogenic mechanism of renal fibrosis and in developing rational intervention strategy.

Tissue-type plasminogen activator (tPA) is a well characterized serine protease whose main function is to proteolytically convert proenzyme plasminogen into biologically active plasmin. Through its catalytic activity, tPA is also involved, directly or indirectly, in the posttransla-

Supported by the National Institutes of Health grants DK061408, DK064005, and DK071040.

Accepted for publication May 28, 2010.

Address reprint requests to Youhua Liu, Ph.D., Department of Pathology, University of Pittsburgh School of Medicine, S-405 Biomedical Science Tower, 200 Lothrop St, Pittsburgh, PA 15261. E-mail: liuy@ upmc.edu. 
tional activation of numerous peptide growth factors, such as hepatocyte growth factor, heparin-binding epidermal growth factor-like growth factor, and transforming growth factor (TGF)- $\beta 1{ }^{15-17}$ Emerging evidence indicates, however, that IPA is able to exert a multitude of cellular actions by a mechanism independent of its protease activity. ${ }^{18-21}$ We have previously shown that TPA binds to the plasma membrane LDL receptor-related protein 1 (LRP-1) and induces its tyrosine phosphorylation. ${ }^{22}$ This triggers a series of intracellular signal transduction events, leading to the induction of matrix metalloproteinase-9 gene expression. ${ }^{22,23}$ Therefore, it appears that tPA can transmit its extracellular signal across the plasma membrane and regulates specific gene expression in the nucleus by a mode of action similar to that elicited by a cytokine. ${ }^{22}$

In normal kidney, tPA level is extremely low and its mRNA expression is limited to endothelial cells, glomerular podocytes, and the epithelial cells of the distal collecting ducts. ${ }^{24}$ However, tPA expression is markedly induced after obstructive injury, predominantly in interstitial fibroblasts. ${ }^{22,25}$ Clinical studies also document that the circulating levels of tPA are elevated in patients with renal insufficiency, compared with healthy controls. ${ }^{26}$ Increased expression of tPA appears detrimental, as genetic ablation of tPA protects kidney against development of renal fibrosis in obstructive nephropathy. ${ }^{27}$ tPA has been shown to prolong the lifespan of interstitial fibroblasts by protecting them from apoptosis and to potentiate myofibroblastic activation, ${ }^{25,28}$ which likely leads to an exaggerated fibroblast pool in diseased kidney. However, whether IPA also directly regulates fibroblast proliferation remains completely unknown.

In the current study, we demonstrate that tPA promotes renal interstitial fibroblast proliferation via a cascade of signaling events involving $\beta 1$ integrin and its downstream focal adhesion kinase (FAK). Our results suggest that tPA is a potent fibroblast mitogen that plays a critical role in controlling the size of fibrogenic cell population in diseased kidney.

\section{Materials and Methods}

\section{Antibodies and Reagents}

The rabbit antibodies against phospho-specific FAK (Tyr925), total FAK, and phospho-specific extracellular signal-regulated protein kinase (ERK)1/2 (Thr202/Tyr204) were purchased from Cell Signaling Technology (Beverly, MA). Rabbit anti-total ERK1/2 and mouse monoclonal anti- $\alpha$-tubulin antibodies were obtained from Sigma (St. Louis, MO). Rabbit anti-proliferating cell nuclear antigen (PCNA) and anti-c-myc antibodies were purchased from Santa Cruz Biotechnology (Santa Cruz, CA). Mouse anti-CyclinD1 antibody (clone DCS-6) was obtained from NeoMarkers (Fremont, CA). Rabbit polyclonal anti- $\alpha$ smooth muscle actin ( $\alpha$-SMA) was purchased from Abcam Inc (ab5694; Cambridge, MA). The secondary horseradish peroxidase-conjugated antibodies were obtained from Sigma and Chemicon (Temecula, CA), re- spectively. Recombinant human single-chain tPA was purchased from American Diagnostica (Stamford, CT). The nonenzymatic tPA (ne-tPA) was supplied by Molecular Innovations (Southfield, MI). The recombinant human TGF- $\beta 1$ was obtained from R\&D Systems (Minneapolis, MN). FAK inhibitor PF573228 (category number 3239) was purchased from Tocris Bioscience (Bristol, UK). Integrin-linked kinase (ILK) inhibitor QLT-0267 was provided by QLT Inc. (Vancouver, BC, Canada). The $\beta 1$ integrin specific blocking antibody (clone 4B4) was obtained from Beckman Coulter (Fullerton, CA). Mek1 inhibitor PD98059 was purchased from Calbiochem-Novabiochem (La Jolla, CA). Bromodeoxyuridine (BrdU) was obtained from Sigma. Cell culture media, fetal bovine serum, and supplements were purchased from Invitrogen (Carlsbad, CA). All other chemicals were of analytic grade and were obtained from Sigma or Fisher (Pittsburgh, PA), unless otherwise indicated.

\section{Cell Culture and Treatments}

Normal rat kidney interstitial fibroblasts (NRK-49F), mouse homozygous LRP-deficient embryonic fibroblasts (PEA-13), and wild-type mouse embryonic fibroblasts (MEF-1) were purchased from the American Type Culture Collection (Manassas, VA) and maintained as described previously. ${ }^{28}$ Briefly, NRK-49F cells were cultured in Dulbecco's modified Eagle's medium/Ham's F12 (1:1) supplemented with $5 \%$ fetal bovine serum, while PEA-13 and MEF-1 were incubated in Dulbecco's modified Eagle's medium with supplements specified by the American Type Culture Collection. Cells were seeded onto six-well plates in complete medium and incubated overnight, and then changed to serum-free medium for serum-starvation for 24 hours. Recombinant human single-chain tPA was added to the culture medium at different concentrations for various periods of time as indicated. For control group, cells were treated with vehicle alone. In some experiments, cells were pretreated for 30 minutes with chemical inhibitors at the specified concentrations, followed by subsequent treatment with vehicle, tPA or netPA, respectively.

\section{Adenovirus Infection and Small-Interfering RNA Inhibition}

NRK-49F cells were infected with adenoviral vector for ILK (Ad-Flag-ILK) and $\beta$-galactosidase (Ad-LacZ), as described previously. ${ }^{25,29}$ For small-interfering RNA (siRNA) inhibition studies, NRK-49F cells were transiently transfected with either rat FAK-specific siRNA (SMARTpool L-090463-01-0010; Dharmacon, Lafayette, CO) or control siRNA (AM4611; Ambion, Austin, TX) by using oligofectamine reagent according to the instructions specified by the manufacturer (Invitrogen). At 4 hours after transfection, cells were treated with or without tPA $(20 \mathrm{nmol} / \mathrm{L})$ for another 48 hours. Whole-cell lysates were prepared for Western blot analysis by using various antibodies as indicated. 


\section{Animal Model}

Homozygous tPA knockout (tPA ${ }^{-1-}$ ) and wild-type $\left(\mathrm{tPA}^{+/+}\right)$mice were described previously, ${ }^{27}$ and subjected to unilateral uretal obstruction (UUO) by using established procedures. ${ }^{30}$ The age- and sex-matched $\mathrm{tPA}^{-1-}$ and $\mathrm{tPA}^{+/+}$mice weighing 20 to $22 \mathrm{~g}$ (four animals per group) underwent UUO through ligating the left ureter by using 4-0 silk after a midline abdominal incision, as described elsewhere. ${ }^{27}$ The right, contralateral unobstructed kidneys served as controls. One day before sacrifice, mice were injected intraperitoneally with BrdU (100 mg/kg body weight). Mice were sacrificed at day 7 after UUO, and the kidneys were removed. One part of the kidney was fixed in 10\% phosphate-buffered formalin followed by paraffin embedding for histological and immunohistochemical studies. Another part was immediately frozen in Tissue-Tek OCT compound for cryosection. The remaining kidneys were snap-frozen in liquid nitrogen and stored at $-80^{\circ} \mathrm{C}$ for tissue homogenates preparation. Animal studies were performed by using an approved protocol by the Institutional Animal Care and Use Committee at the University of Pittsburgh.

\section{Cell Counting and MTT Assay}

Cell numbers were counted by using a hemacytometer. Cell proliferation was also determined quantitatively by a MTT [3-4,5-dimethylthiazol-2-yl]-2,5-diphenyltetrazolium bromide] assay. Briefly, NRK-49F cells were seeded in 96-well plate at a density of $2 \times 10^{3} /$ well. After adherence of cells, the cultures were changed to the serum free medium for 24 hours. The cells were then treated without or with IPA at various concentrations for 48 hours as indicated. MTT ( $5 \mathrm{mg} / \mathrm{ml}$ ) was added to the medium at $10 \mu \mathrm{l}$ per well, followed by incubation at $37^{\circ} \mathrm{C}$ for 4 hours. After the medium was removed, cells were lysed with 100 $\mu$ l dimethyl sulfoxide. Absorbance of each well was measured by a microplate reader at $490 \mathrm{~nm}$.

\section{Flow Cytometry}

NRK-49F cells were seeded at a density of $1 \times 10^{6} /$ well in six-well plates. The serum-starved cells were treated with $\mathrm{tPA}(20 \mathrm{nmol} / \mathrm{L})$ for 24 hours and then fixed in icecold $75 \%$ ethanol at $-20^{\circ} \mathrm{C}$ overnight. After washing, the cells were resuspended in PBS containing $0.1 \%$ Triton $\mathrm{X}-100,0.05 \mathrm{mg} / \mathrm{ml}$ of DNase-free RNase, and $50 \mu \mathrm{g} / \mathrm{ml}$ propidium iodide in the dark at $37^{\circ} \mathrm{C}$ for 30 minutes. Cellular DNA contents were analyzed in the Coulter Epics XL-MCL flow cytometer (Beckman Coulter, Inc, CA). Data were analyzed by using ModFit LT version 3.1 (Verity Software House, Topsham, ME).

\section{BrdU Incorporation}

The effect of tPA on NRK-49F cell proliferation was also evaluated by BrdU incorporation. Briefly, cells were seeded onto collagen I-coated coverslips and incubated for 36 hours in Dulbecco's modified Eagle's medium/F12 medium, and then pulsed with BrdU (10 $\mu \mathrm{mol} / \mathrm{L})$ for 24 hours. Cells were fixed with ice-cold $70 \%$ ethanol for 20 minutes, and DNA was denatured by incubation with 2.5 $\mathrm{N} \mathrm{HCL}$ for 20 minutes, followed by neutralization with 0.1 $\mathrm{M}$ boric acid. Endogenous peroxidase activity was quenched by incubating the cell with $3 \% \mathrm{H}_{2} \mathrm{O}_{2}$ in PBS for 20 minutes, and nonspecific binding was blocked by incubating the cells with $10 \%$ donkey serum for 10 minutes at room temperature, as described previously. ${ }^{31}$ Incorporated BrdU was detected with a mouse monoclonal anti-BrdU antibody, followed by incubation with cyanine CY3-conjugated, affinity-purified secondary antibodies (Jackson ImmunoResearch Laboratories, West Grove, PA). Nonimmune IgG that replaced primary antibody served as a negative control. Stained cells were mounted with Vectashield anti-fade mounting media by using DAPI (4',6-diamidino-2-phenylindole, $\mathrm{HCl}$ ) to visualize the nuclei (Vector Laboratories, Burlingame, CA). Cryosections of mouse kidneys at $5-\mu \mathrm{m}$ thickness were immuno-stained for in vivo BrdU incorporation by using similar methods. For double immunostaining, kidney cryosections were fixed, denatured by incubation with $2.5 \mathrm{~N} \mathrm{HCl}$, followed by neutralization with $0.1 \mathrm{M}$ boric acid, and blocked as described above. The sections were then stained by primary anti- $\alpha$-SMA (Abcam) and anti-BrdU antibodies overnight, followed by staining with fluorescein isothiocyanate- and CY3-conjugated secondary antibodies. Stained samples were viewed by using an Eclipse E600 epifluorescence microscope equipped with a digital camera (Nikon, Melville, NY). BrdU-positive cells were counted and expressed as a percentage of total NRK-49F cells after treatments or as the numbers of positive cells in a high power field of kidney sections.

\section{Western Blot Analysis}

NRK-49F cells were treated as indicated and lysed into radioimmunoprecipitation assay buffer supplemented with protease and phosphatase inhibitor cocktails (Sigma). After centrifugation to remove cell debris, supernatant was mixed with SDS loading buffer. Samples were then heated at $100^{\circ} \mathrm{C}$ for 5 to 10 minutes before loading, separated through $10 \%$ and $15 \%$ SDS polyacrylamide gels, and subjected to Western blot as described previously. ${ }^{31}$ The preparation of kidney tissue homogenates and Western blot analysis of protein expression were performed by using routine procedures as described previously. ${ }^{32}$

\section{Immunohistochemistry Staining}

Immunohistochemical staining of kidney sections was performed by an established protocol. Paraffin-embedded kidney tissue was sectioned at $5-\mu \mathrm{m}$ and then subjected to staining with mouse anti-BrdU antibody. Briefly, tissue sections were deparaffinized, hydrated, and subjected to antigen-retrieval, before endogenous peroxidase activity was quenched by $3 \% \mathrm{H}_{2} \mathrm{O}_{2}$. Tissue sections were then blocked with $10 \%$ normal goat serum, followed by incubating with anti-mouse BrdU antibody overnight at $4^{\circ} \mathrm{C}$. After incubation with secondary antibody for 1 hour, 

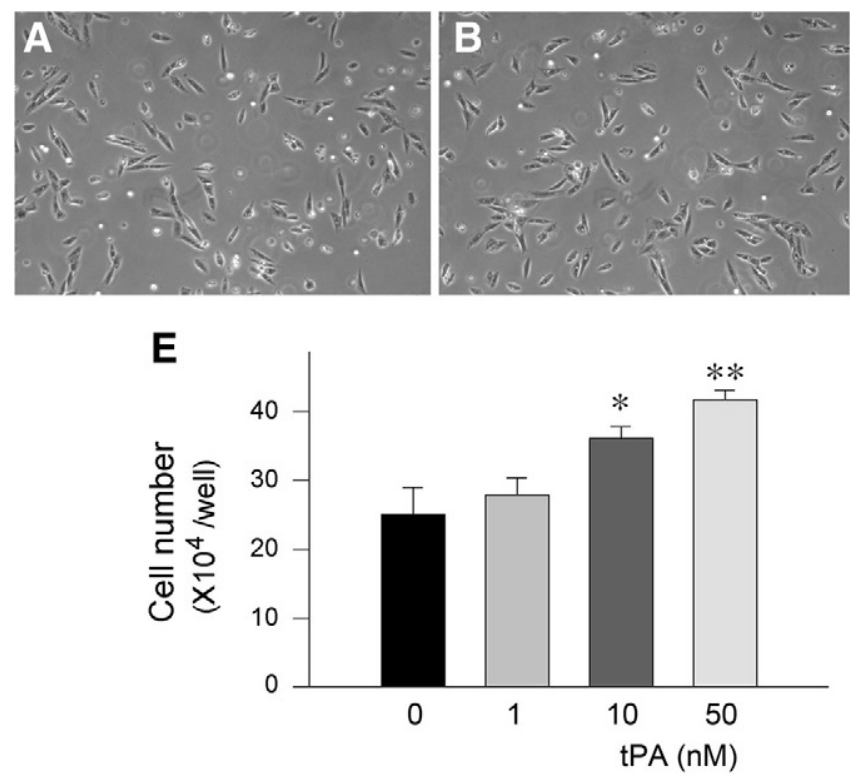
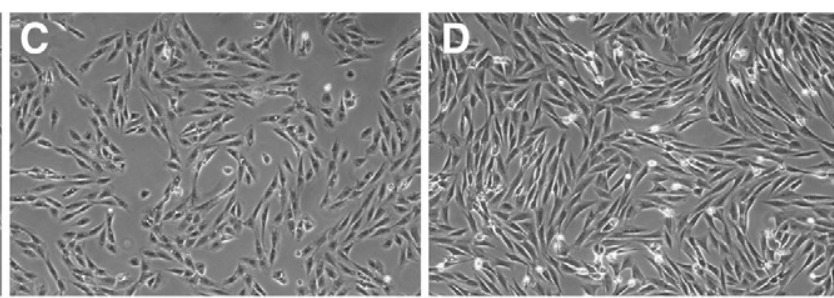

$\mathbf{F}$

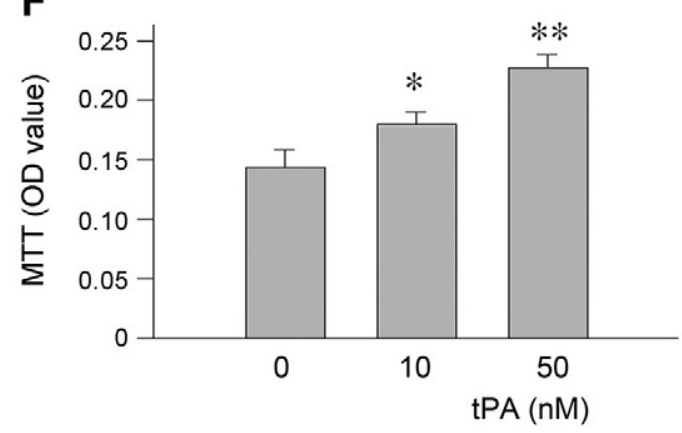

Figure 1. tPA promotes renal interstitial fibroblast proliferation. A-D: NRK- $49 \mathrm{~F}$ cells were incubated with different concentrations of tPA for 48 hours Representative micrographs show the phase-contrast images of NRK-49F cells after treatment without $(\mathbf{A})$ or with $1 \mathrm{nmol} / \mathrm{L}(\mathbf{B}), 10 \mathrm{nmol} / \mathrm{L}(\mathbf{C})$, and $50 \mathrm{nmol} / \mathrm{L}$ tPA (D), respectively. E: Cell numbers after treatment for 48 hours with different concentrations of tPA as indicated. F: Cell growth assessed by a colorimetric MTT assay. ${ }^{*} P<0.05,{ }^{* *} P<0.01$ versus controls $(n=3)$.

sections were then incubated with 3-amino-9-ethylcarbazole reagents for 10 to 20 minutes at room temperature and then mounted in aqueous mounting medium and viewed by using the Eclipse E600 microscope.

\section{Statistical Analyses}

All data were expressed as mean $\pm \mathrm{SD}$. Statistical analyses of the data were performed by using SigmaStat software (Jandel Scientific Software, San Rafael, CA). Comparison between groups was made by using one-way analysis of variance followed by the Student-Newman-Keuls test. In some cases, $t$-test was performed between two groups. $P<0.05$ was considered statistically significant.

\section{Results}

\section{tPA Promotes Renal Interstitial Fibroblast Proliferation}

We first examined whether tPA affects the proliferation of renal interstitial fibroblasts. To this end, NRK-49F cells were incubated with different concentrations of tPA for 2 days. As shown in Figure 1, A-D, tPA promoted renal fibroblast proliferation in a dose-dependent manner. An appreciable increase in NRK-49F cell density was observed after tPA treatment, as illustrated in the phasecontrast images. Cell counting revealed that tPA substantially increased the numbers of NRK-49F cells after 2 days of incubation, starting at a dose of $10 \mathrm{nmol} / \mathrm{L}$ (Figure 1E). Quantitative determination of cell proliferation by a colorimetric MTT assay produced similar results (Figure 1F).

We further investigated the ability of tPA to promote renal fibroblast cell proliferation by assessing the rate of DNA synthesis, as reflected by BrdU incorporation. As illustrated in Figure 2A, an increased BrdU incorporation was clearly evident in NRK-49F cells after incubation with tPA for 48 hours, compared with the controls. Quantitative assessment also revealed that, following tPA treatment, the percentages of BrdU-positive cells were significantly increased (Figure 2B). These results demonstrate that tPA is a potent mitogen that promotes renal interstitial fibroblast cell proliferation.

\section{tPA Accelerates Cell Cycle Progression in Fibroblasts}

We also examined the effects of tPA on the cell cycle progression of NRK-49F cells by a flow cytometry analysis. As shown in Figure 3A, the majority of NRK-49F cells were quiescent and in G0/G1 phase after serum starvation. However, incubation with tPA caused a significant progression of cell cycle, with a marked increase in the percentage of cells in $\mathrm{S}$ and $\mathrm{G} 2 / \mathrm{M}$ phases, compared with the controls (Figure 3, B and C). Together with BrdU incorporation data (Figure 2), these results indicate that tPA is capable of promoting $\mathrm{G} 1$ to $S$ phase transition in renal interstitial fibroblasts, leading to an increased cell proliferation.

\section{tPA Induces the Expression of Numerous Proliferation-Related Genes}

To delineate the mechanism underlying tPA-mediated fibroblast proliferation, we next investigated the expression of numerous proliferation-related genes in NRK-49F cells. As shown in Figure 4A, the proteins of c-fos, c-myc, PCNA, and cyclin D1 were dramatically induced by TPA in NRK-49F cells in a time-dependent fashion. Notably, 

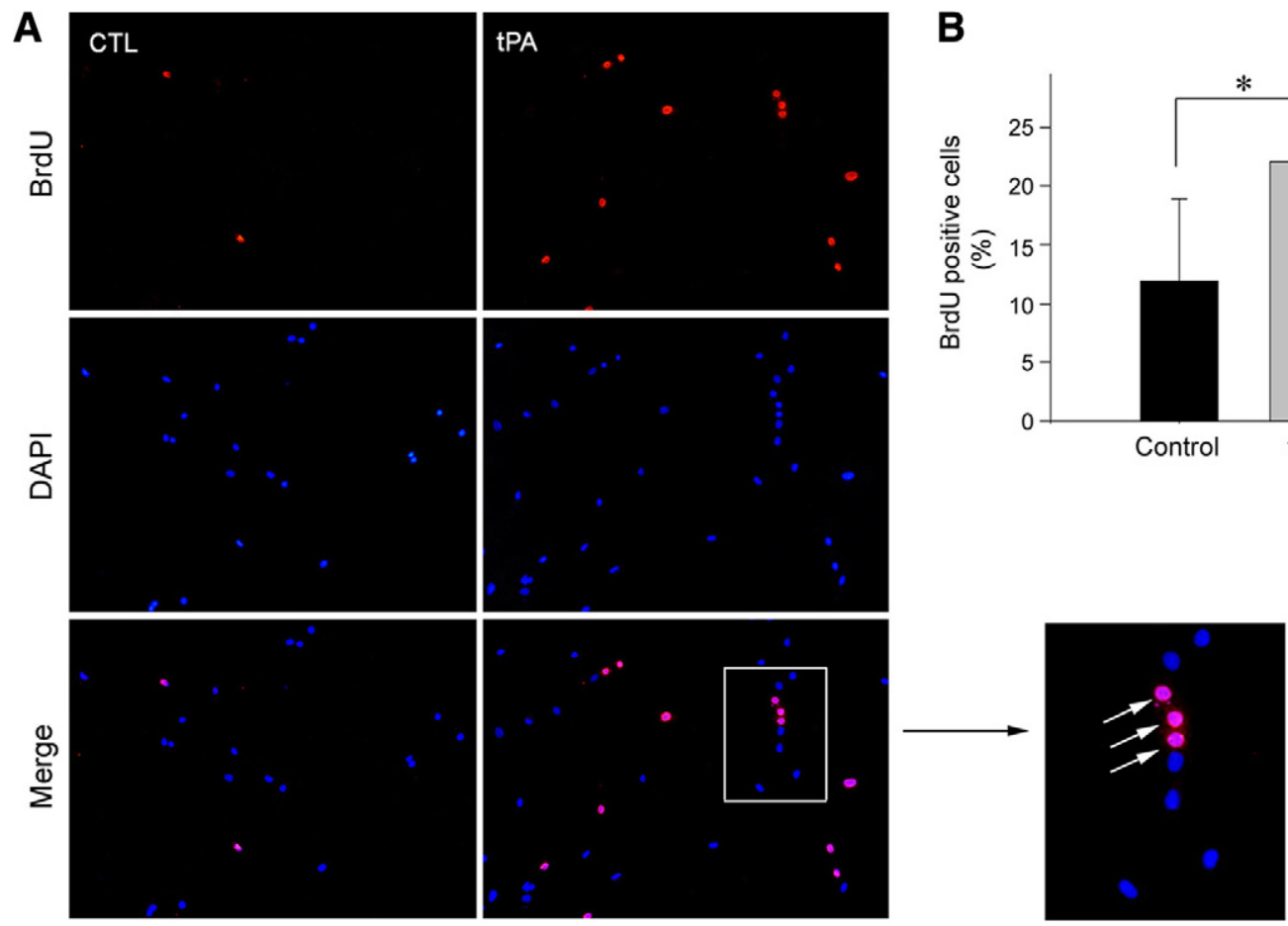

Figure 2. tPA promotes renal fibroblast cell DNA synthesis and BrdU incorporation. A: Representative micrographs show an increased BrdU incorporation in NRK-49F cells after incubation with $50 \mathrm{nmol} / \mathrm{L}$ tPA for 48 hours. Cells were immunostained with mouse anti-BrdU antibody (red). DAPI (blue) was used to visualize the nuclei. Arrows in the inset indicate BrdU-positive cells. B: Quantitative data show the percentages of BrdU-positive cells in control and tPA-treated groups. ${ }^{*} P<0.05$ versus controls $(n=3)$.

these proteins exhibited distinctive expression patterns after tPA treatment (Figure 4B). The induction of c-fos by tPA was rapid, with a first peak at 0.5 hours that immediately returned to baseline level, and a second wave of
A

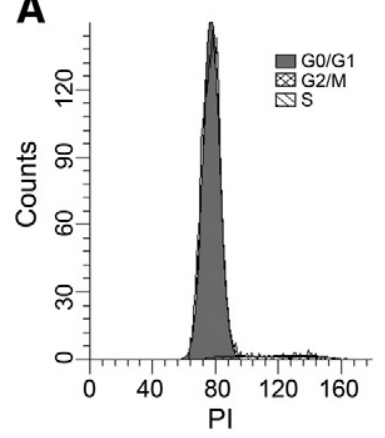

B

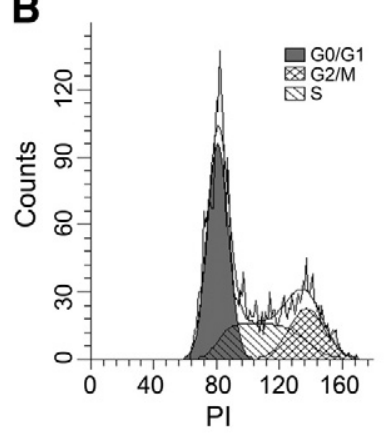

C

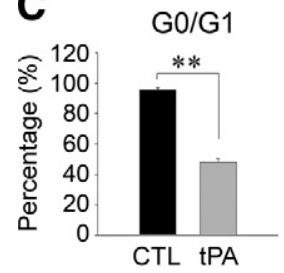

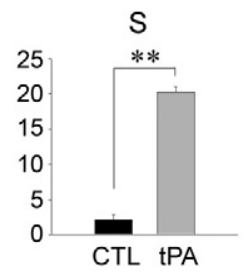

Figure 3. tPA accelerates renal fibroblast cell cycle progression with an increased $\mathrm{S}$ and $\mathrm{G} 2 / \mathrm{M}$ phase entry. $\mathbf{A}$ and $\mathbf{B}$ : Representative histograms illustrate the cell cycle progression by a flow cytometry analysis. NKR-49F cells were treated with or without $50 \mathrm{nmol} / \mathrm{L}$ tPA for 24 hours. G0/G1, S, and $\mathrm{G} 2 / \mathrm{M}$ phases are indicated in the histograms. C: Quantitative data show the distribution of the different phases in cell cycle after treatment with tPA for 24 hours. Data were expressed as the percentage of the cells in a particular phase. ${ }^{* *} P<0.01$ versus controls $(n=3)$. induction starting at 12 hours. Similar induction patterns for c-myc and PCNA in NRK-49F cells were observed, with a slight and sustained increase from 0.5 to 6 hours, followed by a further induction from 12 hours onwards. In contrast, cyclin D was only induced significantly at 48 hours after tPA stimulation (Figure 4, A and B).

Earlier studies have shown that tPA is able to activate the ERK $1 / 2,{ }^{22,28}$ key mitogen-activated protein (MAP) kinases that play a central role in regulating cell proliferation. This prompted us to test whether ERK $1 / 2$ signaling is responsible for the induction of the proliferation-related genes by tPA in NRK-49F cells. As shown in Figure 4C, tPA induced a transient ERK1/2 phosphorylation and activation in NRK-49F cells. Blockade of ERK1/2 activation by PD98059, a specific inhibitor of ERK1/2 upstream kinase Mek1, abolished the tPA-mediated induction of proliferation-related genes (Figure 4D). As a result, inhibition of ERK1/2 also abrogated NRK-49F cell proliferation induced by tPA, as shown by cell counting and MTT assay (Figure 4, E and F). Of note, PD98059 alone at the concentration used did not affect cell viability and proliferation (data not shown). Collectively, these results suggest that tPA induces the proliferation-related gene expression and promotes fibroblast proliferation by a mechanism dependent of ERK1/2 signaling.

\section{The Mitogenic Effect of tPA Is Independent of Its Protease Activity}

tPA is a unique serine protease that possesses both protease activity and cytokine properties. ${ }^{18,22}$ To deter- 
A

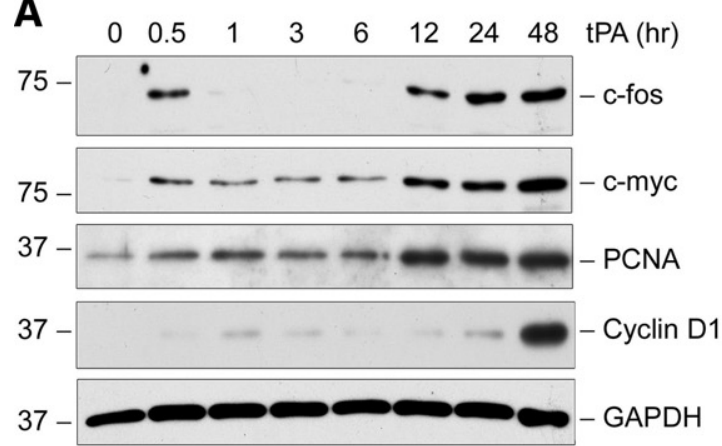

B

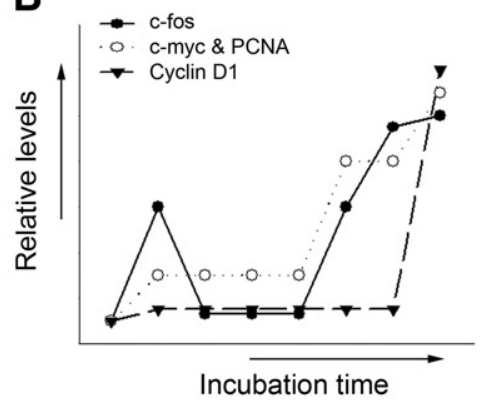

C

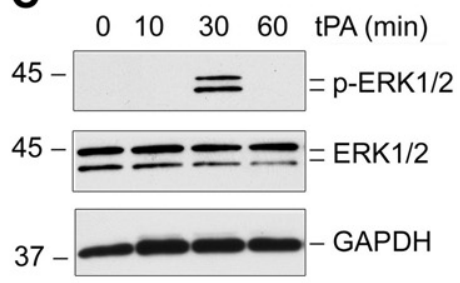

D

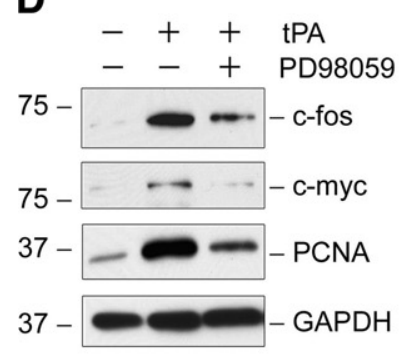

E

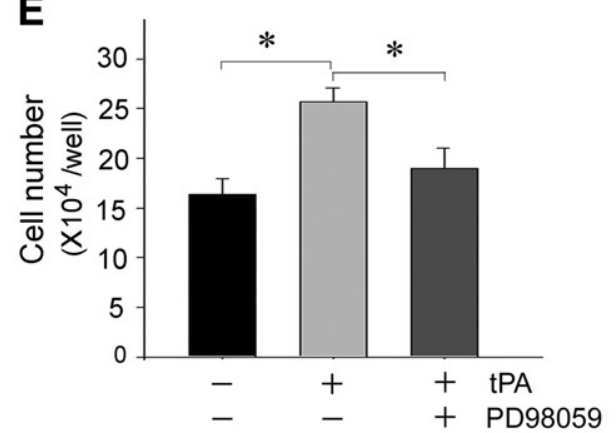

$\mathbf{F}$

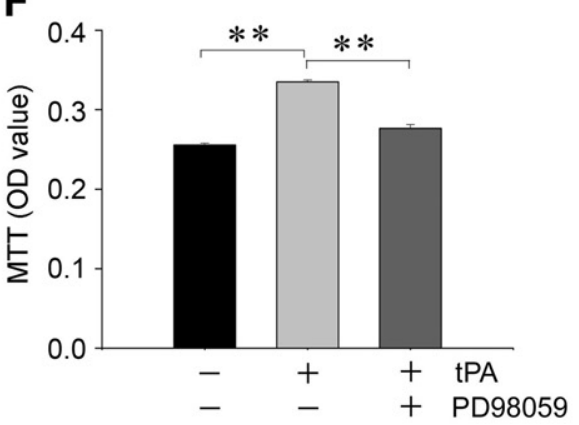

Figure 4. tPA induces the expression of numerous proliferation-related genes in a MAP kinase-dependent manner. A: Representative Western blots show the expression of numerous proliferation-related genes. NRK-49F cells were incubated with tPA ( $20 \mathrm{nmol} / \mathrm{L})$ for various periods of time as indicated and then subjected to Western blot analyses for c-fos, c-myc, PCNA, cyclin D1, and glyceraldehyde-3-phosphate dehydrogenase (GAPDH), respectively. B: Graphic presentation depicts the expression pattern of different genes in renal fibroblasts after tPA treatment. Three induction patterns of gene expression were noted. C: tPA induces ERK1/2 phosphorylation in NRK-49F cells. Cell lysates were immunoblotted with specific antibodies against phospho-ERK1/2, total ERK1/2, and GAPDH, respectively. D: Blockade of ERK1/2 activation abolishes the expression of the proliferation-related genes. NRK- $49 \mathrm{~F}$ cells were pretreated with the specific MEK1 inhibitor PD98059 $(20 \mu \mathrm{mol} / \mathrm{L})$ for 30 minutes, followed by incubation with tPA. E and F: Blockade of ERK1/2 activation abrogates the mitogenic action of tPA. Cell number counting (E) and a colorimetric MTT assay (F) were performed 48 hours after various treatments as indicated. ${ }^{*} P<0.05$; ${ }^{* * *} P<0.01(n=3$ ).

mine whether its protease activity is required for mediating its mitogenic action, we incubated NRK-49F cells with an ne-tPA, which has the serine within the active site of the enzyme mutated to alanine, rendering it catalytically inactive. We found that ne-tPA, similar to its wild-type counterpart, retained the ability to promote NRK-49F cell proliferation, as demonstrated by phase-contrast images (Figure 5, A and B) and cell counting (Figure 5C). Western blot analyses revealed that ne-tPA also induced PCNA and cyclin D1 (Figure 5D), as well as C-fos and C-myc expression (data not shown). Furthermore, inhibition of ERK1/2 signaling by PD98059 also abolished ne-tPA-mediated induction of proliferationrelated genes such as c-fos, c-myc, PCNA, and cyclin D1 in NRK-49F cells (data not shown). In short, it is clear that the mitogenic action of tPA is independent of its protease activity.

\section{tPA-Mediated Cell Proliferation Requires LRP-1 and $\beta 1$ Integrin Signaling}

Our previous studies suggested that the cytokine function of tPA is mediated by the membrane receptor LRP-1 because tPA specifically binds to LRP-1 and triggers its tyrosine phosphorylation. ${ }^{22,25}$ To test whether the mitogenic action of tPA also operates via LRP-1, we used a mouse embryonic fibroblast cell line that is LRP-deficient (PEA-13), and wild-type MEF-1 as a control. Figure 6, A and $\mathrm{C}$, shows that tPA could only induce the proliferationrelated gene expression and cell proliferation in MEF-1 cells, but not in PEA-13 cells lacking LRP-1. LRP-1 phosphorylation on tyrosine residues can lead to the recruitment of $\beta 1$ integrin by facilitating LRP- $1 / \beta 1$ integrin com-
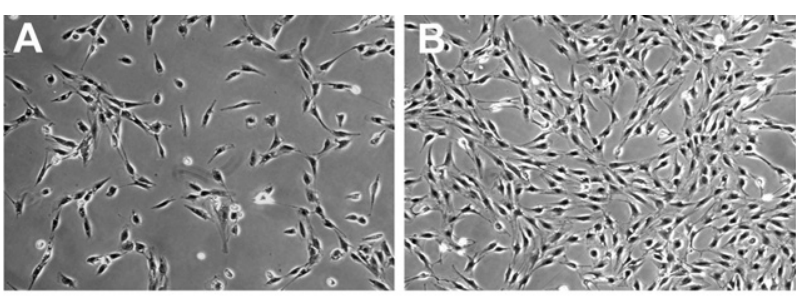

C

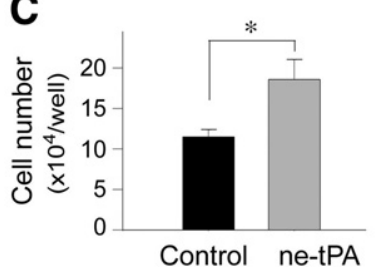

D

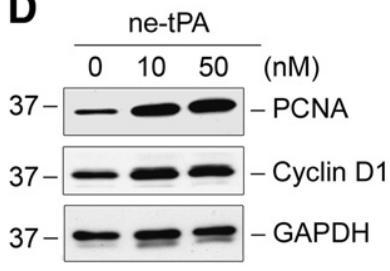

Figure 5. The mitogenic effect of tPA is independent of its protease activity. $\mathbf{A}$ and B: Representative micrographs show the phase-contrast images of NRK-49F cells treated without (A) or with ne-tPA $(50 \mathrm{nmol} / \mathrm{L})(\mathbf{B})$ for 48 hours. C: Quantitative determination of the NRK- $49 \mathrm{~F}$ cell numbers after incubation without or with ne-tPA. ${ }^{*} P<0.05(n=3)$. D: Nonenzymatic tPA also induces the expression of proliferation-related genes. NRK-49F cell lysates were immunoblotted with antibodies against PCNA, cyclin D, and GAPDH, respectively. 

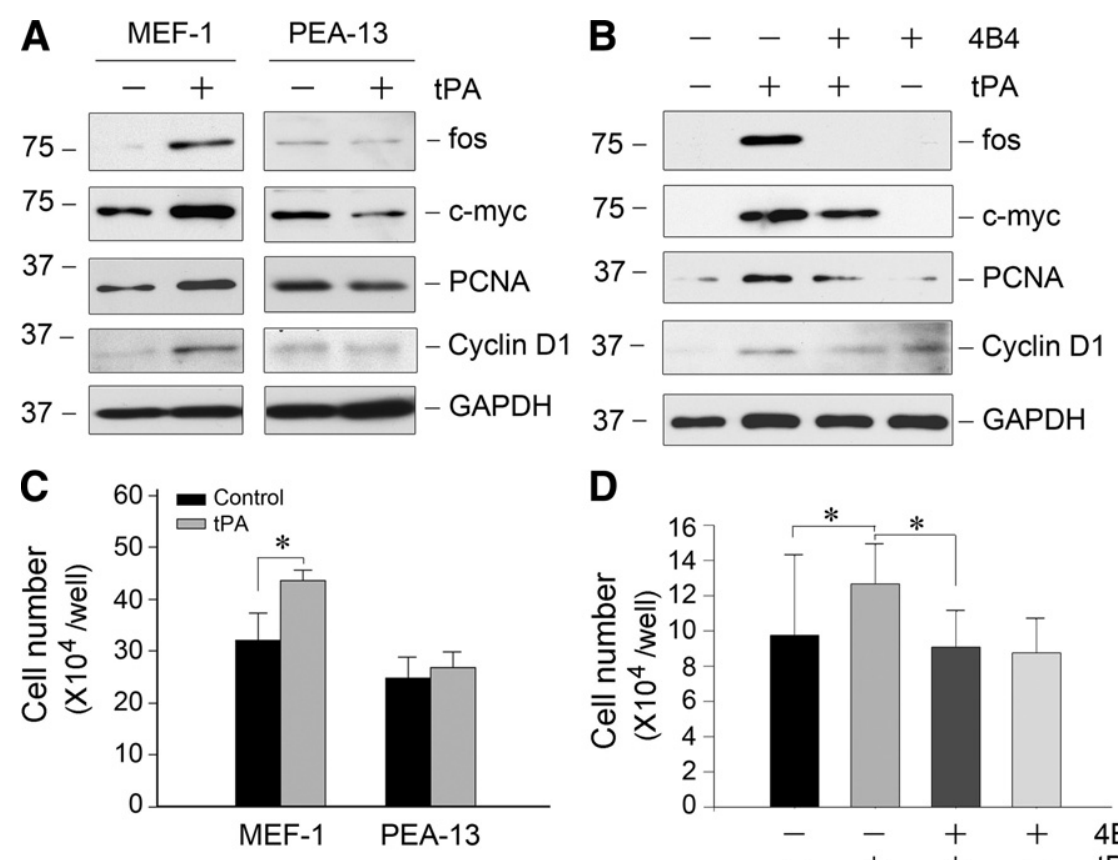

Figure 6. The mitogenic action of tPA requires LRP-1 and $\beta 1$ integrin signaling. A: tPA failed to promote proliferation-related genes expression in LRP-1-deficient fibroblasts. Wild-type MEF-1 and mouse homozygous LRP-deficient embryonic fibroblasts (PEA-13) were treated with 20 $\mathrm{nmol} / \mathrm{L}$ tPA for 48 hours, the expression of various proliferation-related genes was assessed. B: tPA promotion of fibroblast proliferation was dependent on $\beta 1$ integrin signaling. NRK-49F cells were pretreated with or without specific $\beta 1$ integrin blocking antibody (clone 4B4; $10 \mathrm{ng}$ / $\mathrm{ml}$ ) for 30 minutes, then incubated with or without $20 \mathrm{nmol} / \mathrm{L}$ tPA for 48 hours. The expression of various proliferation-related genes was assessed. C: tPA did not promote the proliferation of LRP-1-deficient fibroblasts. MEF-1 and PEA-13 cells were treated with $20 \mathrm{nmol} / \mathrm{L}$ tPA for 48 hours, and then cell numbers were counted. ${ }^{*} P<0.05(n=3)$. D: Blockade of $\beta 1$ integrin signaling abolished tPA promotion of fibroblast proliferation. NRK-49F cells were pretreated with or without specific $\beta 1$ integrin blocking antibody, followed by incubation with or without $20 \mathrm{nmol} / \mathrm{L}$ tPA for 48 hours. Cell numbers were counted. ${ }^{*} P<0.05(n=3)$.

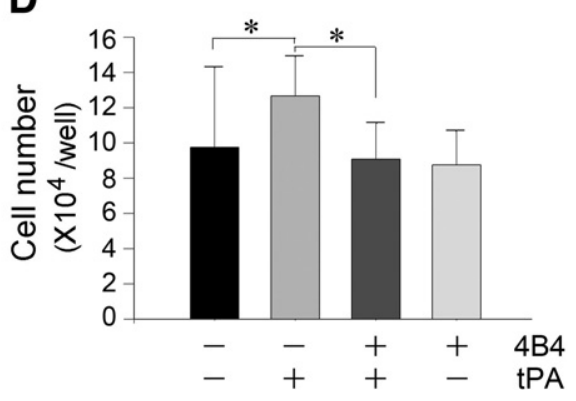

plex formation. ${ }^{25}$ Therefore, we used $4 \mathrm{~B} 4$, a $\beta 1$ integrinspecific blocking antibody to test whether $\beta 1$ integrin is necessary for fibroblast proliferation. As shown in Figure 6 , $B$ and $D$, blockade of $\beta 1$ integrin signaling by 4B4 antibody largely abolished tPA-mediated expression of various proliferation-related genes and inhibited NRK49F fibroblast proliferation.

\section{FAK Activation Is Critical for Mediating tPA-Triggered Fibroblast Proliferation}

Since tPA is known to trigger the LRP-1-mediated recruitment of $\beta 1$ integrin, ${ }^{25}$ we next examined the activation status of FAK, a principal downstream, intracellular protein tyrosine kinase that mediates integrin signaling. As shown in Figure 7A, tPA triggered the rapid phosphorylation of FAK at tyrosine residue 925, starting at 1 minute and reaching a peak at 30 minutes. It is well known that phosphorylation of FAK Tyr925 induces a Ras-dependent activation of the MAP kinase pathway. Hence, we sought to test whether ERK1/2 is downstream of FAK signaling activated by tPA. As shown in Figure 7B, inhibition of FAK by a specific small molecule inhibitor, PF573228, blocked ERK1/2 phosphorylation and activation induced by tPA in NRK-49F cells. Similarly, blockade of FAK signaling by PF573228 abolished the tPA-induced expression of Cfos, c-myc, PCNA, and cyclin D1 (Figure 7, C and F) and subsequent cell proliferation (Figure 7D). Furthermore, knockdown of FAK by siRNA strategy also eradicated tPA-mediated induction of various proliferation-related genes (Figure 7, E and G). Together, these studies strongly indicate that FAK plays an essential role in mediating tPA-triggered fibroblast proliferation.

\section{The Mitogenic Action of tPA Is Independent of ILK Signaling}

We next investigated the potential involvement of ILK, another branch of the integrin signaling pathway, in promoting fibroblast proliferation induced by tPA, as previous studies indicate that ILK signaling is crucial for IPAmediated myofibroblast activation. ${ }^{25}$ NRK-49F cells were treated with specific inhibitors of ILK and FAK, respectively. As shown in Figure 8A, treatment of NRK-49F cells with QLT-0267, a highly selective ILK inhibitor, ${ }^{32}$ did not abolish the ERK1/2 activation induced by tPA. Similarly, blockade of ILK signaling by QLT-0267 did not abolish the tPA-induced c-fos, c-myc, PCNA, and cyclin D1 expression in NRK-49F cells (Figure 8B). Overexpression of exogenous ILK by adenoviral vector in NRK-49F cells also failed to induce the expression of these proliferationrelated genes (Figure $8 \mathrm{C}$ ) as well as cell proliferation (data not shown). Notably, blockade of ERK1/2 signaling did not affect tPA promotion of $\alpha$-SMA expression in NRK-49F cells (Figure 8D), suggesting that tPA promotes renal fibroblast proliferation and myofibroblast activation by independent pathways. Figure $8 \mathrm{E}^{25,28}$ shows the schematic signal pathway mediating the mitogenic action of tPA in renal interstitial fibroblasts.

\section{Ablation of tPA Attenuates Renal Interstitial Cell Proliferation after Injury in Vivo}

To test whether tPA promotes renal fibroblast proliferation in vivo, we used a tPA knockout mouse model in which endogenous tPA is completely ablated. ${ }^{27}$ As shown in Figure 9, A and B, PCNA was markedly induced in the obstructed kidneys of wild-type mice at 7 days after 


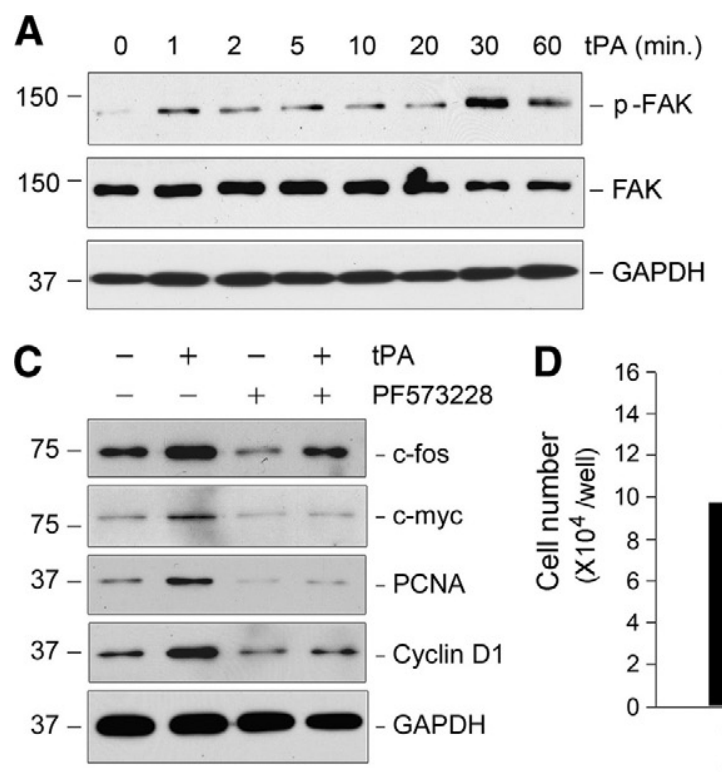

B -+-+ tPA
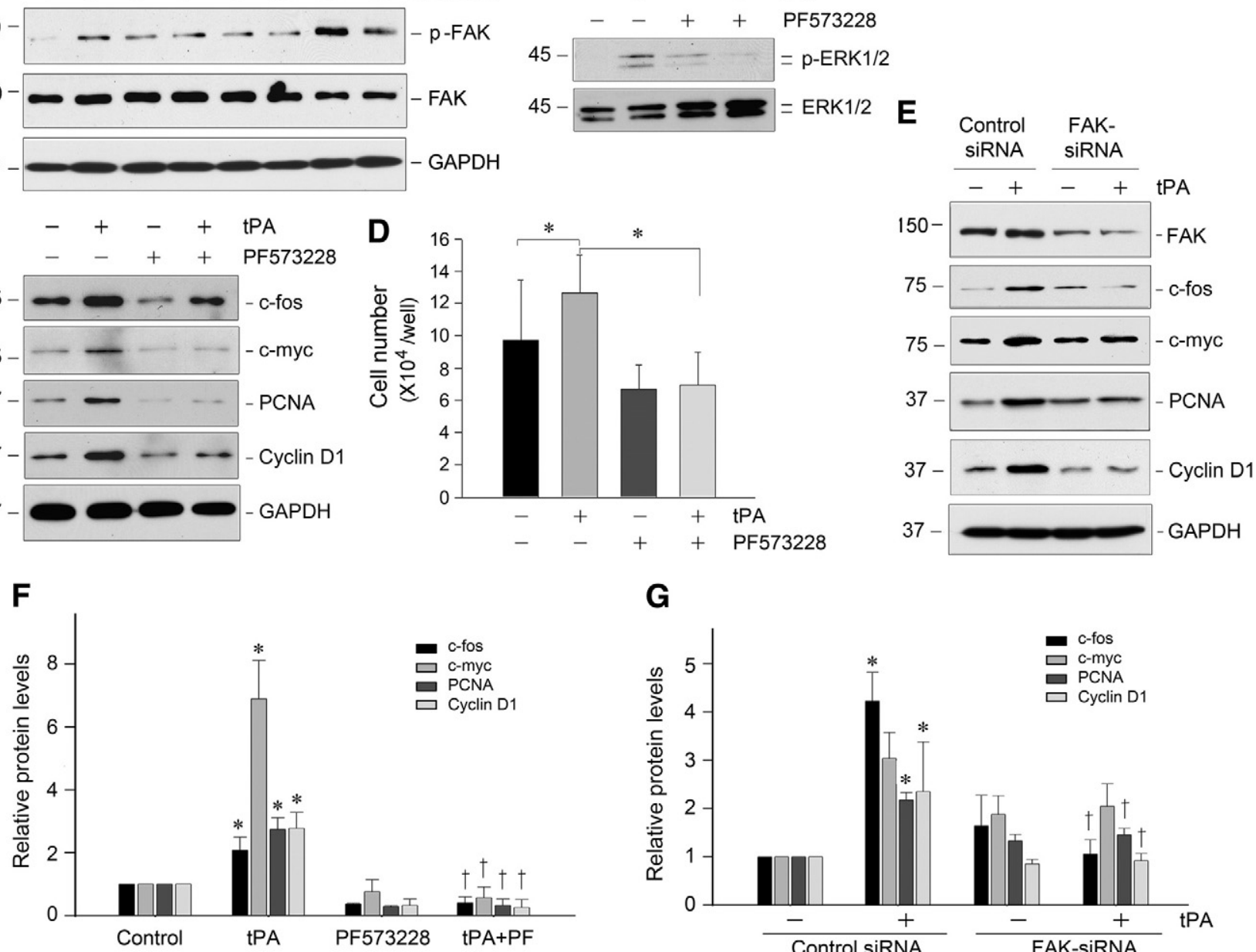

G

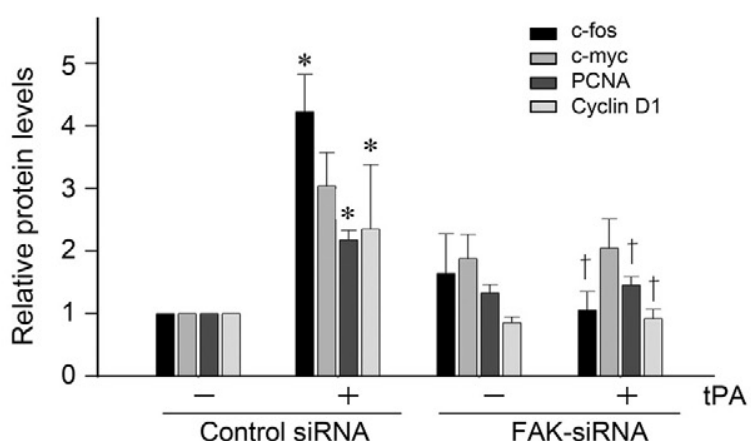

Figure 7. tPA induces renal fibroblast proliferation by a FAK-dependent mechanism. A: tPA induced a rapid FAK tyrosine phosphorylation and activation in renal fibroblasts. NRK-49F cells were treated with tPA $(20 \mathrm{nmol} / \mathrm{L})$ for various periods of time as indicated. Cell lysates were immunoblotted with specific antibodies against phospho-FAK, total FAK, and GAPDH, respectively. B: tPA-mediated ERK1/2 activation was dependent on FAK signaling. NRK-49F cells were pretreated with specific FAK inhibitor PF573228 (10 $\mu \mathrm{mol} / \mathrm{L})$ for 30 minutes, followed by incubation with tPA. C: Blockade of FAK activation abolished the expression of proliferation-related genes induced by tPA. NRK-49F cells were treated as indicated, and cell lysates were subjected to Western blot analyses for c-fos, c- $m y c$, PCNA, cyclin D1, and GAPDH, respectively. D: Blockade of FAK signaling abrogated tPA-mediated cell proliferation. ${ }^{*} P<0.05(n=3)$. E: Knockdown of FAK abolished tPA-mediated induction of various proliferation-related genes. NKR49F cells were transfected with either FAK-specific siRNA or control siRNA, followed by incubation with or without tPA $(20 \mathrm{nmol} / \mathrm{L})$ for 48 hours, respectively. Cell lysates were immunoblotted with specific antibodies as indicated. F and $\mathbf{G}$ : Quantitative data show the proliferation-related protein abundances after various treatments as shown in $\mathbf{C}$ and $\mathbf{E}$, respectively. Relative protein levels (fold induction over controls) were determined by densitometric analyses and reported after normalizing with GAPDH. Data were means \pm SEM of three experiments. ${ }^{*} P<0.05$ versus controls; ${ }^{\dagger} P<0.05$ versus tPA alone $(\mathbf{F})$, or versus control siRNA $(\mathbf{G})$.

UUO, compared with contralateral unobstructed control kidneys. However, PCNA levels were significantly reduced in the obstructed kidney of $\mathrm{PPA}^{-/-}$mice (Figure 9, $A$ and $B$ ). To better detect the proliferating cells in vivo, we used a BrdU incorporation assay to identify the kidney cells undergoing active DNA synthesis. As shown in Figure $9, \mathrm{C}-\mathrm{G}$, a marked increase in the numbers of BrdUpositive cells was observed in the obstructed kidney of wild-type mice at 7 days after UUO (Figure 9, E versus D). However, the numbers of renal BrdU-positive cells in the $\mathrm{tPA}^{-1-}$ mice were significantly reduced under the same conditions (Figure 9, G versus E). Quantitative determination of the BrdU-positive cells confirmed a significant decrease of the proliferative cells in the kidneys of $\mathrm{tPA}^{-/-}$ mice after injury (Figure 9C). Similar results were obtained when kidney sections were immunohistochemically stained with anti-BrdU antibody (Figure 9, $\mathrm{H}$ and I).
Of note, the BrdU-positive cells were largely localized in the interstitium of the obstructed kidneys (Figure 9, $\mathrm{H}$ and I, arrows). To elucidate the identity of these proliferating cells, we performed a double-staining for BrdU and $\alpha$-SMA. As shown in Figure 9, J-L, the vast majority of the BrdU-positive proliferating cells were indeed $\alpha$-SMA-positive myofibroblasts in the obstructed kidney. Therefore, it appears clear that tPA is also able to promote interstitial fibroblast/myofibroblast proliferation in vivo.

\section{Discussion}

One of the hallmarks in the pathogenesis of renal interstitial fibrosis is the relentless expansion of the matrixproducing fibroblasts, causing an excessive accumulation of extracellular matrix components in the injured 

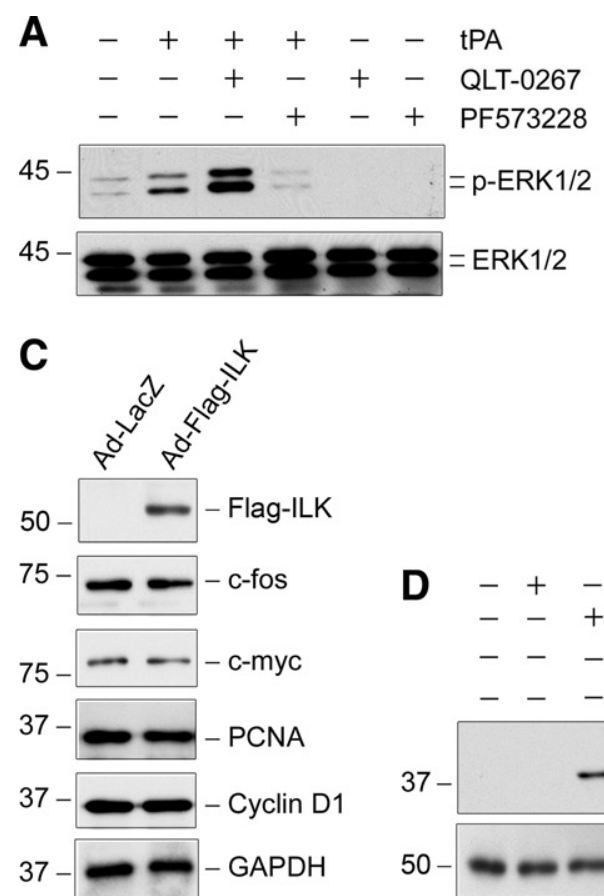

$\begin{array}{llllllll}\mathbf{B} & - & + & + & + & - & - & \mathrm{tPA} \\ & - & - & + & - & + & - & \mathrm{QLT}-0267 \\ - & - & - & + & - & + & \text { PF573228 }\end{array}$
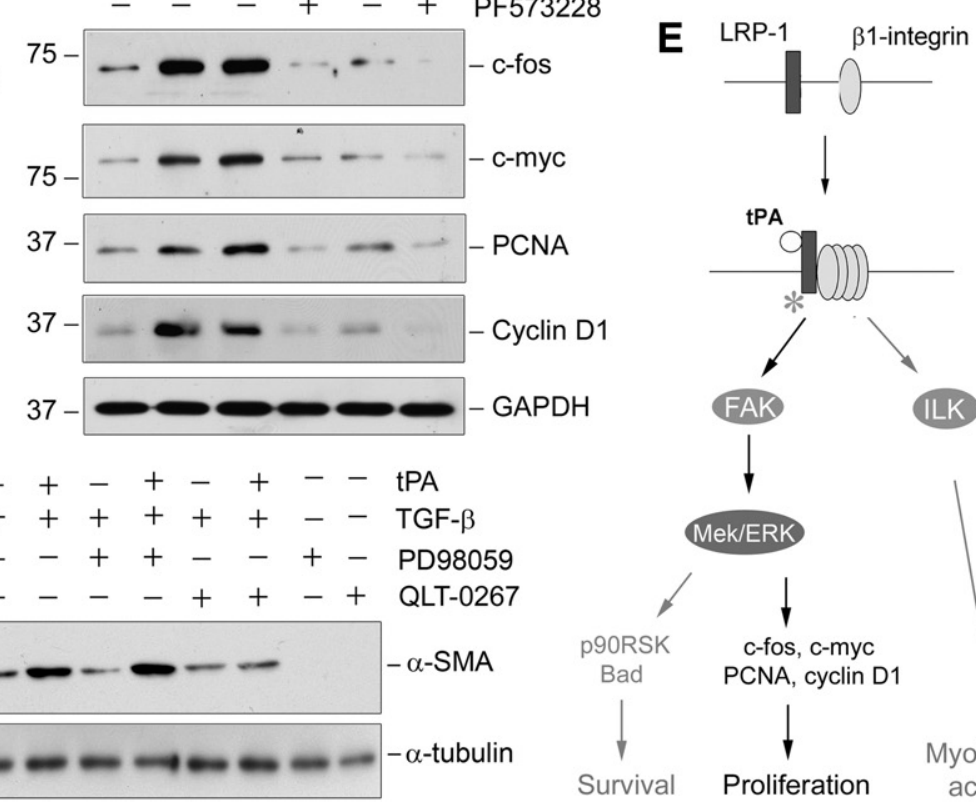

D -+-+-+-+-- tPA
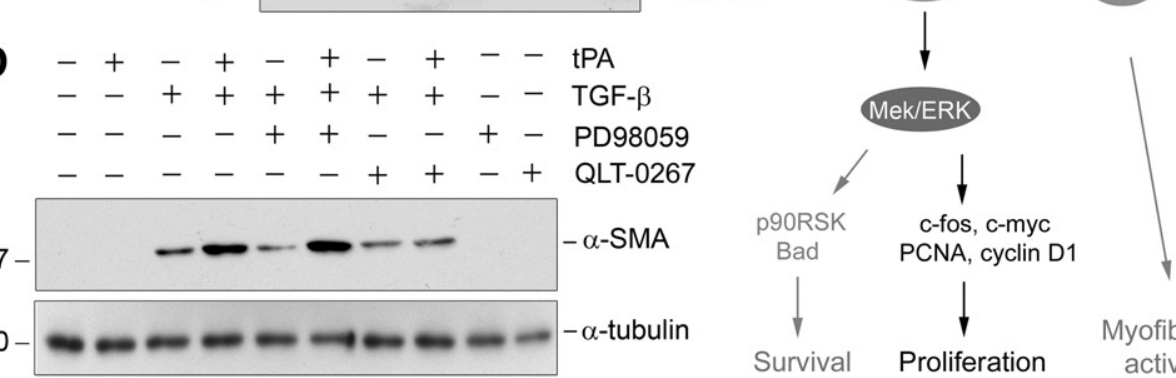

Figure 8. tPA-triggered fibroblast proliferation is independent of ILK. A: Blockade of ILK, another branch of $\beta 1$ integrin signaling, with specific inhibitor QLT-0267 did not abolish tPA-mediated ERK1/2 phosphorylation and activation. NRK-49F cells were pretreated with or without ILK inhibitor QLT-0267 or FAK inhibitor PF573228 for 30 minutes, followed by incubation with or without tPA $(20 \mathrm{nmol} / \mathrm{L})$ for 30 minutes. B: Inhibition of ILK by QLT-0267 also failed to abolish the tPA-induced expression of $\mathrm{c}$-fos, c- $m y$ c, PCNA and cyclin D1 genes. NRK-49F cells were incubated without or with tPA $(20 \mathrm{nmol} / \mathrm{L})$ for 48 hours in the absence or presence of QLT-0267 and PF573228 as indicated, respectively. C: Ectopic expression of exogenous ILK failed to induce proliferation-related gene expression in renal fibroblasts. NRK-49F cells were infected with adenoviral vector for Flag-tagged ILK (Ad-Flag-ILK) and $\beta$-galactosidase (Ad-LacZ), respectively. Cell lysates were immunoblotted with specific antibodies against Flag, c-fos, c- myc, PCNA, cyclin D1, and GAPDH. D: Blockade of ERK1/2 signaling did not affect tPA promotion of $\alpha$-SMA expression. NRK-49F cells were treated with tPA $(10 \mathrm{nmol} / \mathrm{L})$, TGF- $\beta 1(0.5 \mathrm{ng} / \mathrm{ml})$, and PD98059 $(20 \mu$ mol/L) as indicated. Cell lysates were immunoblotted with specific antibodies against $\alpha$-SMA and GAPDH, respectively. E: Schematic diagram shows the signal pathways mediating the mitogenic action of tPA in renal interstitial fibroblasts. After binding to its membrane receptor LRP-1, tPA induces its tyrosine phosphorylation, which leads to the recruitment of $\beta 1$ integrin, as shown previously. ${ }^{25}$ This results in activation of FAK, which in turn stimulates the MAPK pathway, leading to expression of numerous proliferation-related genes such as c-fos, c-myc, PCNA, and cyclin D1. The role and relevant pathways of tPA in regulating fibroblast survival and myofibroblastic activation (gray arrows) are as elucidated previously. ${ }^{25,28}$ Open circle denotes tPA; asterisk indicates LRP-1 tyrosine phosphorylation.

kidney. This increase in extracellular matrix accumulation and deposition progressively occupies the tubulointerstitial space and eventually destroys normal renal parenchyma. In this study, we have identified tPA as a potent mitogen for renal interstitial fibroblasts, and demonstrated that the mitogenic action of TPA is independent of its protease activity. We further show that TPA is able to trigger FAK tyrosine phosphorylation in renal fibroblasts, leading to the activation of its downstream MAP kinase pathway, thereby inducing expression of proliferationrelated genes and cell proliferation. These results are consistent with the emerging concept that IPA can function as a cytokine that transmits its signal from the extracellular compartment to the nucleus by triggering a cascade of intracellular signaling events. ${ }^{18,22}$ Given that IPA expression is markedly induced in interstitial fibroblasts after injury, it is conceivable that its mitogenic action may play a critical role in promoting fibroblast proliferation and expansion as seen in diseased kidney.

Interstitial fibroblasts in normal kidney are quiescent and predominantly in the G0/G1 phase of the cell cycle. After tPA stimulation, they apparently re-enter the cell cycle, resulting in a decrease of cells in the G0/G1 phase and an increase in those that are in S and G2/M (Figure $3)$. This effect of tPA on fibroblast cell cycle progression was also confirmed by an increase in BrdU incorporation
(Figure 2), which inevitably leads to cell replication. Of note, tPA stimulates fibroblast proliferation in a magnitude similar to, if not greater than, that elicited by TGF- $\beta 1$ (data not shown), a well characterized fibroblast mitogen. ${ }^{33}$ This suggests that TPA is a potent and perhaps major fibroblast mitogen in vivo. Consistent with this notion, kidney in tPA null mice displays a significant decrease in interstitial myofibroblast proliferation after obstructive injury (Figure 9), despite no significant difference in renal TGF- $\beta 1$ activation between IPA null mice and their wild-type controls. ${ }^{27}$

Cell proliferation triggered by IPA is accompanied by an induction of numerous genes such as c-fos, c-myc, PCNA, and cyclin D1 (Figure 4), suggesting that, akin to other classic mitogens, tPA is able to induce expression of multiple proliferation-related genes in the nucleus. Of interest, the expression pattern of the genes induced by tPA is quite divergent. Although c-fos induction by IPA occurs rapidly, with the first peak at 30 minutes, the stimulation of cyclin D1 in NRK-49F cells only takes place after a 48-hour long incubation. These results are not unanticipated, as c-fos is the prototype of the so-called early immediate genes whose expression after mitogen stimulation is immediately induced, quickly returns to baseline, and is followed by a second wave of induction. ${ }^{34,35}$ The c-fos gene product is a major component of 
A

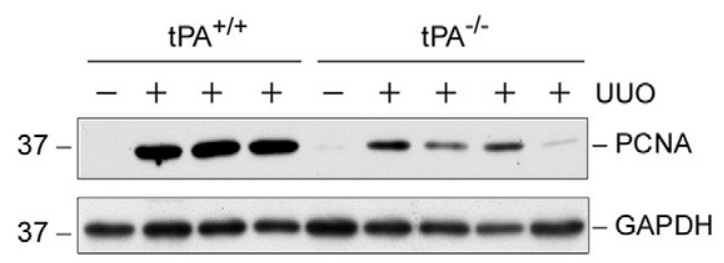

B

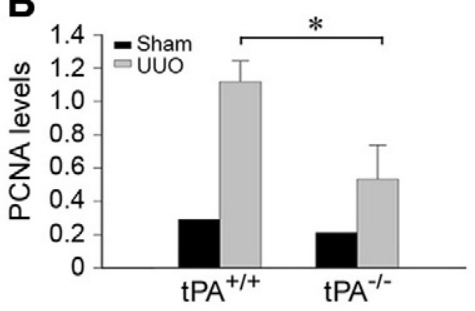

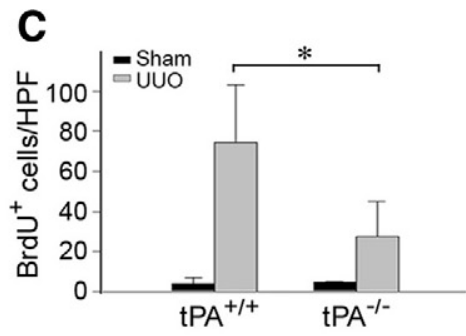
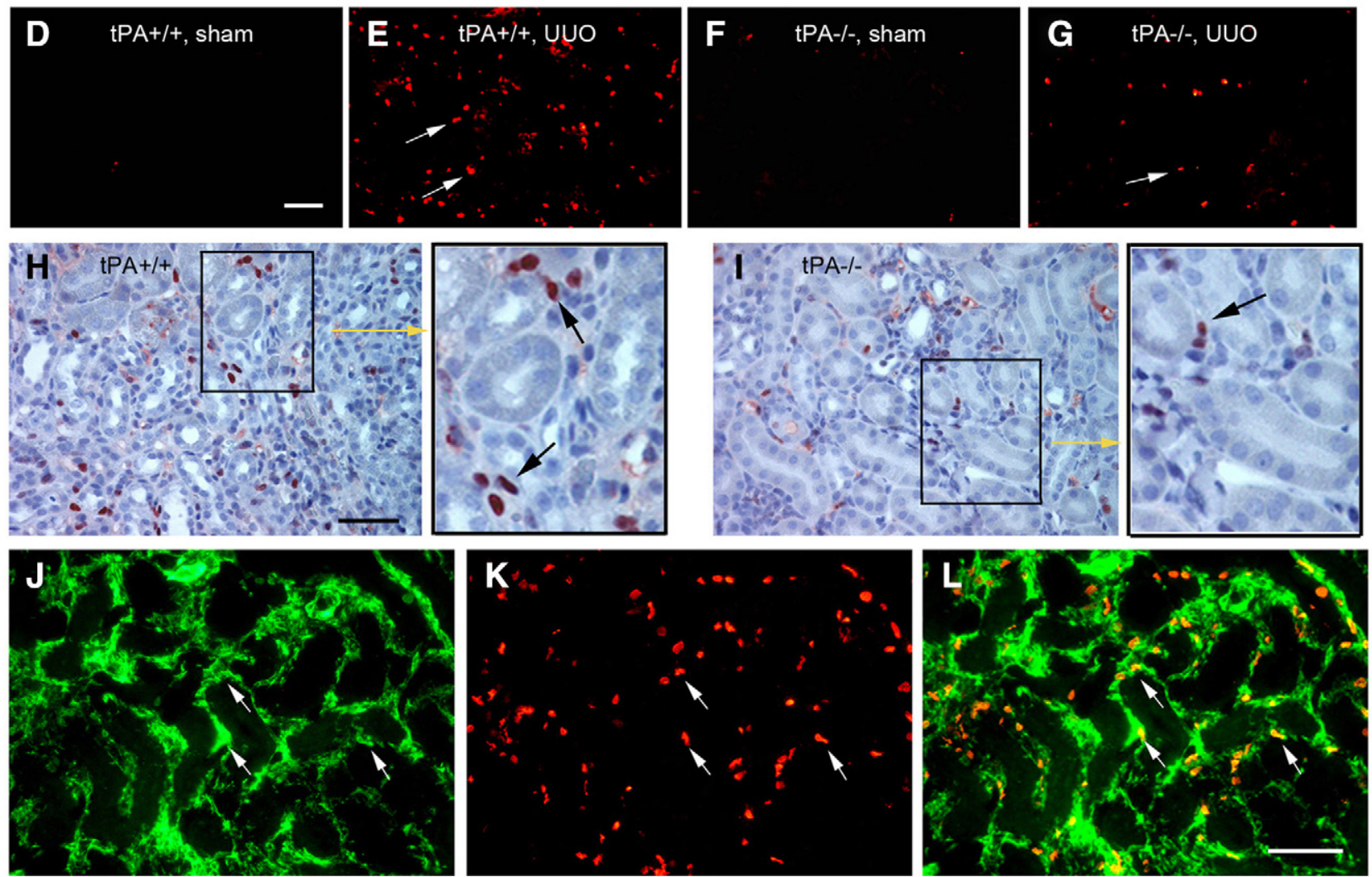

Figure 9. Ablation of tPA in mice attenuates interstitial fibroblast proliferation after obstructive injury. A: Western blot analyses show a reduced renal PCNA expression in $\mathrm{tPA}^{-/-}$mice after obstructive injury, compared with wild-type controls. Kidney homogenates from both $\mathrm{tPA}^{+/+}$and tPA ${ }^{-/-}$mice at seven days after UUO were assayed for PCNA expression. Contra-lateral intact kidney served as control. B: Quantitative determination of the relative abundance of PCNA protein among various groups. Data are mean \pm SD of four animals per group. ${ }^{*} P<0.05$. C: Quantitative data on the number of BrdU-positive cells in different groups as indicated. Data were expressed as BrdU-positive cells per high power field (HPF), and presented as mean \pm SD. ${ }^{*} P<0.05, n=4$. D-G: Representative micrographs show the BrdU-positive cells (red) by immunofluorescence staining. Mice were injected with BrdU one day before sacrifice. Arrows indicate BrdU-positive cells. Scale bar $=50 \mu \mathrm{m}$. $\mathbf{H}$ and I: Immunohistochemical staining shows a predominantly interstitial localization of the BrdU-positive cells in the $\mathrm{tPA}^{+/+}(\mathbf{H})$ and $\mathrm{PPA}^{-/-}$mice $(\mathbf{I})$ at day 7 after UUO. Arrows in the inset indicate BrdU-positive cells. Scale bar $=50 \mu \mathrm{m}$. $\mathbf{J}-\mathbf{L}$ : Double immunostaining

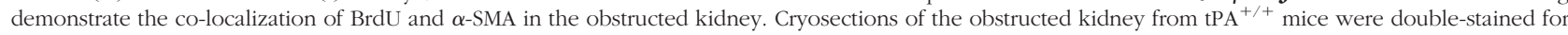
$\alpha$-SMA (green, $\mathbf{J}$ ) and BrdU (red, $\mathbf{K}$ ), respectively. Merge of the images was presented as $\mathbf{L}$. Arrows indicate the proliferative myofibroblasts positive for both BrdU and $\alpha$-SMA. Scale bar $=50 \mu \mathrm{m}$.

the AP-1 transcription factor complex that controls the transcriptional activation of many target genes. It is worthwhile to point out that the cyclin D1 gene promoter harbors a functional AP-1 binding site, and it therefore is likely that $\mathrm{C}$-fos induced by tPA is responsible for subsequent cyclin D1 gene expression. ${ }^{36,37}$ Functionally, each of the four genes induced by tPA plays a critical role in regulating cell proliferation on their own, ${ }^{38-40}$ and together, they could constitute a core set of mitogenic regulators that elicit a concerted action, leading to accelerated cell cycle progression and fibroblast proliferation.

The results presented in this study also provide significant insights into the mechanism by which tPA promotes fibroblast proliferation. Earlier studies have shown that
tPA binds to LRP-1, a multifunctional scavenger and signaling receptor, ${ }^{41,42}$ and induces rapid tyrosine phosphorylation on its $\beta$ subunit. ${ }^{22}$ Phosphorylated LRP-1 recruits $\beta 1$ integrin by forming a complex with it, leading to the clustering and activation of $\beta 1$ integrin signaling in renal interstitial fibroblasts. ${ }^{25}$ tPA is also known to induce ERK $1 / 2$ and its upstream kinase Mek1 phosphorylation and activation. ${ }^{22}$ In this study, we demonstrate that the ERK $1 / 2$ activation by TPA is coupled to $\beta 1$ integrin signaling through FAK (Figure 7), a cytoplasmic protein tyrosine kinase that plays a central role in mediating integrin signaling. ${ }^{43,44}$ It is well established that activation of FAK by integrin clustering leads to its autophosphorylation at Tyr397, which in turn results in the phosphoryla- 
tion of Tyr925 in the carboxyl-terminal region of FAK through recruitment of Src family kinases. ${ }^{43}$ Phosphorylation of FAK at Tyr925 creates a binding site for the Grb2/SH2 domain and triggers a Ras-dependent activation of the MAP kinase pathway. ${ }^{45}$ Indeed, a rapid phosphorylation of FAK at Tyr925 is observed in NRK-49F cells after tPA stimulation (Figure 7). More importantly, blockade of FAK activation by specific small molecule inhibitor or knockdown FAK expression by siRNA abolishes the IPA-induced ERK $1 / 2$ activation, proliferationrelated gene expression, and fibroblast proliferation. In this context, it appears conceivable that FAK and its downstream MAP kinase pathway play an essential role in mediating fibroblast proliferation induced by tPA.

There are two major downstream effector kinases, namely FAK and ILK, that transmit $\beta 1$ integrin signaling and mediate its cellular actions, and both of them are evolutionarily conserved and ubiquitously expressed in a wide variety of cells. Unlike FAK, which is a tyrosine kinase, ILK is an intracellular serine/thernine protein kinase that plays an important role in mediating cell adhesion, migration, epithelial to mesenchymal transition, and matrix production. ${ }^{46-49}$ We have previously demonstrated that IPA promotes myofibroblast activation and matrix production by a mechanism that is dependent on the LRP-1-mediated recruitment of $\beta 1$ integrin/ILK signaling. ${ }^{25}$ However, ILK appears not to be involved in IPAinduced fibroblast proliferation, as neither inhibition of ILK by a specific inhibitor nor ectopic expression of exogenous ILK affects the expression of proliferation-related genes (Figure 8). Interestingly, blockade of ERK1/2 signaling does not affect tPA-mediated promotion of $\alpha$-SMA expression (Figure 8D), suggesting that tPA-mediated fibroblast proliferation and myofibroblastic transformation are controlled by two parallel, independent pathways. Therefore, as shown in Figure 8E, only FAK, but not the ILK, branch of $\beta 1$ integrin signaling is implicated in the regulation of tPA-mediated fibroblast proliferation. It is worthwhile to point out that downstream signaling of FAK, namely the ERK1/2/p90RSK/Bad cascade, is also important in promoting tPA-mediated fibroblast survival, as previously reported. ${ }^{28}$ Collectively, these observations indicate that FAK and ILK, two different branches of $\beta 1$ integrin signaling, are selectively responsible for the tPA-mediated cell proliferation/survival and myofibroblast activation/matrix production, respectively. Of note, tPA-triggered ERK1/2 activation apparently mediates both interstitial fibroblast proliferation (Figure 8E) and matrix metalloproteinase-9 induction in NRK-49F cells, ${ }^{22}$ whether these two events are functionally linked remains to be determined.

In summary, this study, together with previous reports, ${ }^{25,28}$ has established that tPA, a serine protease whose expression is induced in fibrotic kidney, is a fibrogenic mediator that promotes fibroblast proliferation, survival, and myofibroblast activation through $\beta 1$ integrinmediated signaling cascades. The challenges ahead are how to translate this knowledge into new therapeutic strategies, thereby eventually benefitting the patients with fibrotic kidney diseases.

\section{References}

1. Liu Y: Renal fibrosis: new insights into the pathogenesis and therapeutics. Kidney Int 2006, 69:213-217

2. Eddy AA: Progression in chronic kidney disease. Adv Chronic Kidney Dis 2005, 12:353-365

3. Hewitson TD: Renal tubulointerstitial fibrosis: common but never simple. Am J Physiol Renal Physiol 2009, 296:F1239-F1244

4. Grande MT, Lopez-Novoa JM: Fibroblast activation and myofibroblast generation in obstructive nephropathy. Nat Rev Nephrol 2009, 5:319-328

5. Strutz F, Zeisberg M: Renal fibroblasts and myofibroblasts in chronic kidney disease. J Am Soc Nephrol 2006, 17:2992-2998

6. Neilson EG: Mechanisms of disease: fibroblasts; a new look at an old problem. Nat Clin Pract Nephrol 2006, 2:101-108

7. Bohle A, Wehrmann M, Mackensen-Haen S, Gise H, Mickeler E, Xiao TC, Muller C, Muller GA: Pathogenesis of chronic renal failure in primary glomerulopathies. Nephrol Dial Transplant 1994, 9(Suppl 3):4-12

8. Bohle A, Wehrmann M, Bogenschutz O, Batz C, Muller CA, Muller GA: The pathogenesis of chronic renal failure in diabetic nephropathy: investigation of 488 cases of diabetic glomerulosclerosis. Pathol Res Pract 1991, 187:251-259

9. Hewitson TD, Wu HL, Becker GJ: Interstitial myofibroblasts in experimental renal infection and scarring. Am J Nephrol 1995, 15:411-417

10. Rodemann HP, Muller GA: Abnormal growth and clonal proliferation of fibroblasts derived from kidneys with interstitial fibrosis. Proc Soc Exp Biol Med 1990, 195:57-63

11. Strutz F, Zeisberg M, Hemmerlein B, Sattler B, Hummel K, Becker V, Muller GA: Basic fibroblast growth factor expression is increased in human renal fibrogenesis and may mediate autocrine fibroblast proliferation. Kidney Int 2000, 57:1521-1538

12. Liu Y: Epithelial to mesenchymal transition in renal fibrogenesis: pathologic significance, molecular mechanism, and therapeutic intervention. J Am Soc Nephrol 2004, 15:1-12

13. Kalluri R, Neilson EG: Epithelial-mesenchymal transition and its implications for fibrosis. J Clin Invest 2003, 112:1776-1784

14. Iwano M, Plieth D, Danoff TM, Xue C, Okada H, Neilson EG: Evidence that fibroblasts derive from epithelium during tissue fibrosis. J Clin Invest 2002, 110:341-350

15. Mars WM, Zarnegar R, Michalopoulos GK: Activation of hepatocyte growth factor by the plasminogen activators UPA and tPA. Am J Pathol 1993, 143:949-958

16. Yee JA, Yan L, Dominguez JC, Allan EH, Martin TJ: Plasminogendependent activation of latent transforming growth factor beta (TGF beta) by growing cultures of osteoblast-like cells. J Cell Physiol 1993, 157:528-534

17. Hurtado M, Lozano JJ, Castellanos E, Lopez-Fernandez LA, Harshman K, Martinez AC, Ortiz AR, Thomson TM, Paciucci R: Activation of the epidermal growth factor signalling pathway by tissue plasminogen activator in pancreas cancer cells. Gut 2007, 56:1266-1274

18. Hu K, Mars WM, Liu Y: Novel actions of tissue-type plasminogen activator in chronic kidney disease. Front Biosci 2008, 13:5174-5186

19. Ortiz-Zapater E, Peiro S, Roda O, Corominas JM, Aguilar S, Ampurdanes C, Real FX, Navarro P: Tissue plasminogen activator induces pancreatic cancer cell proliferation by a non-catalytic mechanism that requires extracellular signal-regulated kinase 1/2 activation through epidermal growth factor receptor and annexin A2. Am J Pathol 2007, 170:1573-1584

20. Cao C, Lawrence DA, Li Y, Von Arnim CA, Herz J, Su EJ, Makarova A, Hyman BT, Strickland DK, Zhang L: Endocytic receptor LRP together with tPA and PAI-1 coordinates Mac-1-dependent macrophage migration. EMBO J 2006, 25:1860-1870

21. Ling C, Zou T, Hsiao Y, Tao X, Chen ZL, Strickland S, Song H: Disruption of tissue plasminogen activator gene reduces macrophage migration. Biochem Biophys Res Commun 2006, 349:906-912

22. Hu K, Yang J, Tanaka S, Gonias SL, Mars WM, Liu Y: Tissue-type plasminogen activator acts as a cytokine that triggers intracellular signal transduction and induces matrix metalloproteinase-9 gene expression. J Biol Chem 2006, 281:2120-2127

23. Wang X, Lee SR, Arai K, Lee SR, Tsuji K, Rebeck GW, Lo EH: Lipoprotein receptor-mediated induction of matrix metalloproteinase by tissue plasminogen activator. Nat Med 2003, 9:1313-1317

24. Roelofs JJ, Rouschop KM, Leemans JC, Claessen N, de Boer AM, 
Frederiks WM, Lijnen HR, Weening JJ, Florquin S: Tissue-type plasminogen activator modulates inflammatory responses and renal function in ischemia reperfusion injury. J Am Soc Nephrol 2006, 17:131-140

25. Hu K, Wu C, Mars WM, Liu Y: Tissue-type plasminogen activator promotes murine myofibroblast activation through LDL receptor-related protein 1-mediated integrin signaling. J Clin Invest 2007, 117:3821-3832

26. Segarra A, Chacon P, Martinez-Eyarre C, Argelaguer X, Vila J, Ruiz P, Fort J, Bartolome J, Camps J, Moliner E, Pelegri A, Marco F, Olmos A, Piera L: Circulating levels of plasminogen activator inhibitor type-1, tissue plasminogen activator, and thrombomodulin in hemodialysis patients: biochemical correlations and role as independent predictors of coronary artery stenosis. J Am Soc Nephrol 2001, 12:1255-1263

27. Yang J, Shultz RW, Mars WM, Wegner RE, Li Y, Dai C, Nejak K, Liu Y: Disruption of tissue-type plasminogen activator gene in mice reduces renal interstitial fibrosis in obstructive nephropathy. J Clin Invest 2002, 110:1525-1538

28. Hu K, Lin L, Tan X, Yang J, Bu G, Mars WM, Liu Y: tPA protects renal interstitial fibroblasts and myofibroblasts from apoptosis. J Am Soc Nephrol 2008, 19:503-514

29. Guo L, Wu C: Regulation of fibronectin matrix deposition and cell proliferation by the PINCH-ILK-CH-ILKBP complex. FASEB J 2002, 16:1298-1300

30. Yang J, Liu Y: Dissection of key events in tubular epithelial to myofibroblast transition and its implications in renal interstitial fibrosis. Am J Pathol 2001, 159:1465-1475

31. Yang J, Dai C, Liu Y: Hepatocyte growth factor suppresses renal interstitial myofibroblast activation and intercepts Smad signal transduction. Am J Pathol 2003, 163:621-632

32. Li Y, Tan X, Dai C, Stolz DB, Wang D, Liu Y: Inhibition of integrin-linked kinase attenuates renal interstitial fibrosis. J Am Soc Nephrol 2009, 20:1907-1918

33. Bottinger EP: TGF-beta in renal injury and disease. Semin Nephrol 2007, 27:309-320

34. Kutz SM, Providence KM, Higgins PJ: Antisense targeting of c-fos transcripts inhibits serum- and TGF-beta 1-stimulated PAI-1 gene expression and directed motility in renal epithelial cells. Cell Motil Cytoskeleton 2001, 48:163-174

35. Sharma SC, Richards JS: Regulation of AP1 (Jun/Fos) factor expression and activation in ovarian granulosa cells: relation of JunD and Fra2 to terminal differentiation. J Biol Chem 2000, 275:33718-33728
36. Fernando R, Foster JS, Bible A, Strom A, Pestell RG, Rao M, Saxton A, Baek SJ, Yamaguchi K, Donnell R, Cekanova M, Wimalasena J: Breast cancer cell proliferation is inhibited by BAD: regulation of cyclin D1. J Biol Chem 2007, 282:28864-28873

37. Toualbi K, Guller MC, Mauriz JL, Labalette C, Buendia MA, Mauviel A Bernuau D: Physical and functional cooperation between AP-1 and beta-catenin for the regulation of TCF-dependent genes. Oncogene 2007, 26:3492-3502

38. Butt AJ, Caldon CE, McNeil CM, Swarbrick A, Musgrove EA, Sutherland RL: Cell cycle machinery: links with genesis and treatment of breast cancer. Adv Exp Med Biol 2008, 630:189-205

39. Morrish F, Isern N, Sadilek M, Jeffrey M, Hockenbery DM: c-Myc activates multiple metabolic networks to generate substrates for cellcycle entry. Oncogene 2009, 28:2485-2491

40. Freemantle SJ, Liu X, Feng Q, Galimberti F, Blumen S, Sekula D, Kitareewan S, Dragnev KH, Dmitrovsky E: Cyclin degradation for cancer therapy and chemoprevention. J Cell Biochem 2007, 102:869-877

41. Herz J, Strickland DK: LRP: a multifunctional scavenger and signaling receptor. J Clin Invest 2001, 108:779-784

42. Montel V, Gaultier A, Lester RD, Campana WM, Gonias SL: The low-density lipoprotein receptor-related protein regulates cancer cell survival and metastasis development. Cancer Res 2007, 67:98179824

43. Mitra SK, Schlaepfer DD: Integrin-regulated FAK-Src signaling in normal and cancer cells. Curr Opin Cell Biol 2006, 18:516-523

44. Schaller MD: FAK and paxillin: regulators of $\mathrm{N}$-cadherin adhesion and inhibitors of cell migration? J Cell Biol 2004, 166:157-159

45. Saleem S, Li J, Yee SP, Fellows GF, Goodyer CG, Wang R: beta1 integrin/FAK/ERK signalling pathway is essential for human fetal islet cell differentiation and survival. J Pathol 2009, 219:182-192

46. Liu Y: New insights into epithelial-mesenchymal transition in kidney fibrosis. J Am Soc Nephrol 2010, 21:212-222

47. Li Y, Yang J, Dai C, Wu C, Liu Y: Role for integrin-linked kinase in mediating tubular epithelial to mesenchymal transition and renal interstitial fibrogenesis. J Clin Invest 2003, 112:503-516

48. Legate KR, Montanez E, Kudlacek O, Fassler R: ILK. PINCH and parvin: the tIPP of integrin signalling. Nat Rev Mol Cell Biol 2006, 7:20-31

49. Hannigan G, Troussard AA, Dedhar S: Integrin-linked kinase: a cancer therapeutic target unique among its ILK. Nat Rev Cancer 2005, $5: 51-63$ 